\title{
O direito à acessibilidade do deficiente visual à luz da lei brasileira de inclusão da pessoa com deficiência
}

\section{The right to accessibility of visually impaired according to the statute for people with disability}

\author{
Clara Gomes Veloso da Silva ${ }^{1}$ \\ Werley Campos Gomes ${ }^{2}$ \\ Agenor Pedro Silva Júnior ${ }^{3}$
}

\begin{abstract}
Resumo
Recentemente foi sancionada em nosso país uma norma legal conhecida como Lei Brasileira de Inclusão da Pessoa com Deficiência (LBI), ou, simplesmente como Estatuto da Pessoa com Deficiência, que passou a ser um dos principais marcos legislativos à proteção dos direitos das pessoas com deficiências. São vários artigos e dispositivos que alteram o tratamento jurídico da questão da deficiência no país, se ancorando no arcabouço dos direitos humanos. Contudo, conforme será demonstrado neste artigo, as limitações dos espaços públicos são inúmeras, dificultando a inclusão social das pessoas com deficiência visual no contexto social e na vida cotidiana. A acessibilidade se torna um tema de grande importância para o planejamento urbano, de modo a garantir uma melhor qualidade de vida a todos os cidadãos que se encontram em situação de necessidade, sendo que qualquer um de nós poderá precisar desses benefícios um dia. Dessa forma, a acessibilidade pode ser considerada como um direito instrumental e fundamental, diretamente ligada ao direito à igualdade.

Palavras-Chave: Proteção. Direitos. Deficiência. Legislação.
\end{abstract}

\begin{abstract}
Recently, a legal norm known as Brazilian Law for the Inclusion of People with Disability or the Statute for People with Disability has been sanctioned in our country, and it has become one of the main legislative framework for the protection of the rights of people with disabilities in Brazil. There are several articles and devices that changed the legal treatment of the disability issue in the country, anchoring in the human rights framework. However, as will be demonstrated in this article, the public spaces's limitations are numerous, making it more difficult the social inclusion of the visually impaired in the social context and in daily life. It is necessary to recognize that accessibility has a huge importance for urban planning, because it can guarantee a better quality of life for all citizens who are in need. Moreover, accessibility can be considered an instrumental and fundamental right, directly linked to the right to equality.
\end{abstract}

Keywords: Protection. Rights. Disability. Legislation.

\footnotetext{
Artigo recebido em 16 de Outubro de 2017 e aprovado em 28 de Fevereiro de 2018.

${ }^{1}$ Acadêmica do Curso de Direito do Centro Universitário de Anápolis - UNIEVANGÉLICA. Bolsista PIBIC 2016/2017. E-mail: claragomessv@gmail.com

${ }^{2}$ Professor de Direito do Centro Universitário de Anápolis - UNIEVANGÉLICA. Advogado. Mestre em Sociedade Tecnologia e Meio Ambiente. E-mail: werley-adv@ hotmail.com

${ }^{3}$ Professor de Direito no Curso de Administração da FECER - UNIEVANGÉLICA. Advogado. Especialista em Finanças pela FGV. E-mail: agenor.junior-adv@outlook.com.
} 


\section{Introdução}

Pouco se discute acerca da acessibilidade e mobilidade dos deficientes visuais. No entanto, como observa Almeida (2016) não é apenas o cadeirante que pode ostentar a condição de pessoa com deficiência com comprometimento de mobilidade, mas também as pessoas com deficiência visual, por conta das grandes dificuldades de percepção do espaço que possuem.

Apesar das barreiras, toda a movimentação e deslocamento dessas pessoas devem ser realizados por elas mesmas, com segurança e autonomia, sem depender de ninguém. Contudo, conforme será demonstrado neste artigo, as limitações dos espaços públicos são inúmeras, dificultando a inclusão social dos deficientes visuais. É importante reconhecer que a deficiência resulta do desajuste entre as características físicas das pessoas e as condições nas quais elas atuam. Assim, "[...] a acessibilidade se torna um tema de grande importância para o planejamento urbano" (LEITE, 2016, p. 246).

Destaca-se que, para Leite (2014), a acessibilidade é direito instrumental. Afinal, sem acesso aos equipamentos urbanos, às escolas, aos postos de saúde, aos transportes públicos, as pessoas com deficiência visual não podem exercer, plenamente, a sua cidadania.

\section{Metodologia}

Diante da importância da acessibilidade para esse grupo de pessoas, buscou-se neste artigo resumir a evolução história da garantia dos direitos das pessoas com deficiência, além de expor a legislação brasileira acerca do tema; e, por fim, demonstrar a valia da acessibilidade e as dificuldades ainda enfrentadas pelos deficientes visuais.

$\mathrm{Na}$ tentativa de responder aos problemas e melhor elucidar os objetivos, buscou-se adotar um conjunto de procedimentos metodológicos, entre os quais a pesquisa por meio da compilação bibliográfica, com o fito de estabelecer o diálogo de fontes, sobrepondo pensamentos convergentes, ou até mesmo divergentes, acerca do tema proposto.

Nesse sentido, as bases teóricas do Direito à Acessibilidade do Deficiente Visual, com seus conceitos e fundamentos teórico-metodológicos, foram apoio fundamental, por meio de orientações por comentarista e juristas especializados em legislação humanitária e em suas observações.

A pesquisa documental foi outro procedimento empregado. Para tanto, a documentação relacionada aos deficientes visuais foi fonte privilegiada nesse trabalho, 
com ênfase em dados estatísticos de órgão oficial e Convenções Internacionais acerca dos direitos humanos, os quais apresentam os processos históricos e os seus reflexos no mundo jurídico. Destacam-se também normas jurídicas de expressivo valor histórico, bem como normas vigentes, tais como: Projetos Legislativos, Emendas Constitucionais, Leis e Constituição Federal, que nos permitem perceber as lutas simbólicas no campo jurídico acerca de direitos dos deficientes visuais.

Essas fontes nos esclarecem, por exemplo, os interesses que se apresentam no campo jurídico e político, em que diferentes fatores evidenciam quais os valores e fatos sociais que a positivação jurídica foi direcionada.

\section{A deficiência visual}

Ao se conceituar deficiência visual, é importante principiar com o que aborda a Organização Mundial da Saúde (OMS). De acordo com Lisboa (2014), a OMS define deficiência como qualquer perda ou anormalidade da estrutura ou função psicológica, fisiológica ou anatômica, e classifica a deficiência visual em gradações ou níveis, quais sejam: deficiência leve, deficiência moderada, deficiência profunda, deficiência severa e perda total.

No Brasil, por sua vez, o Decreto $n^{0} 3.298 / 99$ define deficiência visual nos seguintes termos:

[...] cegueira, na qual a acuidade visual é igual ou menor que 0,05 no melhor olho, com a melhor correção óptica; a baixa visão, que significa acuidade visual entre 0,3 e 0,05 no melhor olho, com a melhor correção óptica; os casos nos quais a somatória da medida do campo visual em ambos os olhos for igual ou menor que $60^{\circ}$; ou a ocorrência simultânea de quaisquer das condições anteriores (BRASIL, 1999).

Nesta linha, para Lisboa, (2014), é considerada deficiência o problema funcional ou estrutural, ou seja, a perda parcial ou total da visão aferida mediante a acuidade visual (o que se vê a determinada distância) e o campo visual (a amplitude da área alcançada pela visão). Resumidamente, conforme Matos (2012), a deficiência visual pode ser definida como a limitação das ações e funções do sistema visual.

Cumpre destacar que a deficiência visual pode ocorrer desde o nascimento ou até os primeiros três anos de vida, quando é considerada congênita, ou pode ser obtida por força de doenças ou acidentes, de forma superveniente. Conforme salienta Lisboa (2014), a perda total da visão, quando decorrente de experiência traumática, gera profundo mal-estar emocional, muito por conta dos transtornos da readaptação pessoal do estilo de vida. 
De acordo com o Instituto Brasileiro de Geografia e Estatística (IBGE), segundo análise feita por Barreto Júnior (2014), o conceito de deficiência vem se modificando para acompanhar as inovações na área da saúde e a forma com que a sociedade se relaciona com a parcela da população que apresenta algum tipo de deficiência.

Segundo os dados do Censo Demográfico realizado em 2010 pelo IBGE, “45.606.048 milhões de pessoas declararam ter pelo menos uma das deficiência investigadas (deficiências visual, auditiva motora, mental ou intelectual), correspondendo a 23,9\% da população brasileira" (BARRETO JÚNIOR, 2014, p. 302).

No que diz respeito exclusivamente à deficiência visual, $18,60 \%$ da população brasileira declarou ter algum tipo de perda ou dificuldade visual, correspondendo à maioria daqueles que se declararam deficientes. Além do mais, o Censo de 2010, apurou que naquele momento $8,3 \%$ da população brasileira apresentava algum tipo de deficiência severa, sendo a maior parte portadora de deficiência visual. Vejamos:

Tabela 1: Pessoas com Deficiência

\begin{tabular}{|c|c|c|c|}
\hline $\begin{array}{l}3,46 \% \text { com } \\
\text { deficiência } \\
\text { visual severa }\end{array}$ & $\begin{array}{c}1,12 \% \text { com } \\
\text { deficiência } \\
\text { auditiva } \\
\text { severa }\end{array}$ & $\begin{array}{c}2,33 \% \text { com } \\
\text { deficiência } \\
\text { motora } \\
\text { severa }\end{array}$ & $\begin{array}{l}1,4 \% \text { com } \\
\text { deficiência } \\
\text { mental ou } \\
\text { intelectual }\end{array}$ \\
\hline
\end{tabular}

Fonte: OLIVEIRA, 2012, p. 06.

Ao se observar o quadro abaixo, percebe-se que a deficiência visual teve maior prevalência em todos os grupos de idade investigados pelo Censo de 2010.

Tabela 2: Deficiência visual em todos os grupos de idade

\begin{tabular}{|l|r|r|r|r|}
\hline & \multicolumn{1}{|c|}{$\begin{array}{c}\text { Deficiência } \\
\text { Visual }\end{array}$} & $\begin{array}{c}\text { Deficiência } \\
\text { Auditiva }\end{array}$ & $\begin{array}{c}\text { Deficiência } \\
\text { Motora }\end{array}$ & $\begin{array}{c}\text { Mental ou } \\
\text { Intelectual }\end{array}$ \\
\hline a 14 anos 64 & $5,3 \%$ & $1,3 \%$ & $1,0 \%$ & $0,9 \%$ \\
Acima de 65 anos & $20,1 \%$ & $4,2 \%$ & $5,7 \%$ & $1,4 \%$ \\
\hline
\end{tabular}

Fonte: OLIVEIRA, 2012, p. 08.

Os dados demonstram também a situação de maior vulnerabilidade das pessoas com deficiência em termos de condições socioeconômicas, quando comparadas com a população como um todo. É possível chegar a esta conclusão ao se analisar os indicadores 
de alfabetização, frequência escolar, nível de instrução e características da ocupação profissional, conforme revela Barreto Júnior (2014, p. 303):

Tabela 3: Deficiência visual em todos os grupos de idade

\begin{tabular}{|c|c|c|}
\hline $\begin{array}{c}\text { Atributo } \\
\text { socioeconômico }\end{array}$ & População total & Pessoas com deficiência \\
\hline Alfabetização & $\begin{array}{l}\text { Taxa de alfabetização das } \\
\text { pessoas de } 15 \text { anos ou mais de } \\
\text { idade foi de } 90,6 \% \text {. }\end{array}$ & $\begin{array}{l}\text { Taxa de alfabetização da } \\
\text { população de } 15 \text { anos ou mais } \\
\text { com pelo menos uma das } \\
\text { deficiências investigadas: essa } \\
\text { taxa se reduz para } \mathbf{8 1 , 7 \%} \text {. }\end{array}$ \\
\hline Frequência escolar & $\begin{array}{l}\text { Grupo etário de } 6 \text { a } 14 \text { anos: taxa } \\
\text { de escolarização das crianças } \\
\text { sem nenhuma das deficiências } \\
\text { investigadas foi de } 96,9 \% \text {. }\end{array}$ & $\begin{array}{l}\text { Grupo etário de } 6 \text { a } 14 \text { anos: taxa } \\
\text { de escolarização das crianças } \\
\text { com pelo menos uma das } \\
\text { deficiências investigadas foi de } \\
\mathbf{9 5 , 1 \% .}\end{array}$ \\
\hline $\begin{array}{l}\text { Nivel de instrução: sem } \\
\text { instrução ou apenas o } \\
\text { fundamental incompleto }\end{array}$ & $\begin{array}{l}\mathbf{3 8}, \mathbf{2} \% \text { das pessoas de } 15 \text { anos } \\
\text { ou mais, que declararam não } \\
\text { ter nenhuma das deficiências } \\
\text { investigadas, não tinha } \\
\text { instrução ou possuía apenas o } \\
\text { fundamental incompleto. }\end{array}$ & $\begin{array}{l}\text { 61,1\% da população de } 15 \\
\text { anos ou mais de idade, } \\
\text { com deficiência, não tinha } \\
\text { instrução ou possuía apenas o } \\
\text { fundamental incompleto. } \\
\text { Diferença de } 22,9 \text { pontos } \\
\text { percentuais. }\end{array}$ \\
\hline $\begin{array}{l}\text { Nível de instrução: ensino } \\
\text { médio completo ou } \\
\text { superior incompleto }\end{array}$ & $\begin{array}{l}\text { Percentual de população de } 15 \\
\text { anos ou mais sem deficiência foi } \\
\text { de } \mathbf{2 9 , 7 \%} \text {. }\end{array}$ & $\begin{array}{l}\text { Percentual de população de } 15 \\
\text { anos ou mais com deficiência foi } \\
\text { de } 17,7 \% \text {. }\end{array}$ \\
\hline $\begin{array}{l}\text { Nível de instrução: ensino } \\
\text { superior }\end{array}$ & $\begin{array}{l}10,4 \% \text { para a população de } 15 \\
\text { anos ou mais sem deficiência. }\end{array}$ & $\begin{array}{l}\text { 6,7\% para a populaçăo de } 15 \\
\text { anos ou mais com deficiência. }\end{array}$ \\
\hline $\begin{array}{l}\text { Nivel de ocupação } \\
\text { profissional }\end{array}$ & $\begin{array}{l}\text { Nivel de ocupação do total de } \\
\text { pessoas de } 10 \text { anos ou mais de } \\
\text { idade foi de } \mathbf{5 3}, \mathbf{3} \% \text {. }\end{array}$ & $\begin{array}{l}\text { Nivel de ocupaçăo do total de } \\
\text { pessoas de } 10 \text { anos ou mais de } \\
\text { idade com pelo menos uma das } \\
\text { deficiências investigadas foi de } \\
\mathbf{4 6 , 2 \%} \text {. }\end{array}$ \\
\hline
\end{tabular}

Fonte: BARRETO JÚNIOR, 2014, p. 303.

Nesta mesma direção, Piovesan (2012) afirma que Organismos Internacionais estimam haver na América Latina e no Caribe cerca de 50 milhões de pessoas com deficiência, $82 \%$ das quais vivendo na pobreza.

Da mesma forma, Madruga (2016) alerta que às pessoas com deficiência são reservadas as taxas de pobreza mais elevadas, piores níveis de saúde e educação, em decorrência, principalmente, das barreiras de acesso aos serviços que se entendem básicos.

\section{Os direitos das pessoas com deficiência}

\subsection{Evolução histórica}

Conforme destaca Leite (2016), a preocupação da sociedade com as pessoas com deficiência não vem de hoje, mas não deixa de ser relativamente recente a melhor conscientização social e jurídica dos problemas que esses indivíduos enfrentam. 
Durante a antiguidade, as pessoas com deficiência eram marginalizadas do processo social. Enquanto os gregos abandonavam as crianças deficientes nas montanhas, os romanos tinham por costume atirá-las nos rios. Além do mais, “[...] considerava-se que a pessoa com deficiência era objeto de feitiçaria, razão pela qual se justificava a sua marginalização ou, até mesmo, o sacrifício” (LISBOA, 2014, p. 346).

Segundo Fonseca (2012), foi a partir da Revolução Industrial que o avanço tecnológico suscitou a compreensão de que as deficiências poderiam ser atendidas por instrumentos adequados. Nesta fase, desenvolveram-se objetos como as muletas, as cadeiras de rodas, a escrita Braille e a codificação das línguas de sinais.

Especificamente em relação aos deficientes visuais, Lisboa (2014) afirma que somente em meados do século XVIII foi lhes dedicada maior atenção, momento em que tiveram oportunidade de ter acesso ao ensino. Mas foi apenas nas décadas de 1970 e 1980 que os movimentos de integração social dos cegos vieram a ter repercussão razoável.

Panoramicamente é possível resumir esta evolução histórica em distintos momentos que se caracterizam, respectivamente, por uma primeira fase de extermínio das pessoas com deficiência, seguida pela exclusão, “[...] até a fase contemporânea, iniciada no século XIX, que se subdivide em integração instrumental, inclusão e, finalmente, emancipação" (FONSECA, 2012, p. 28).

No que se refere aos direitos humanos das pessoas com deficiência, a história da construção destes direitos compreende quatro fases:

a) uma fase de intolerância em relação às pessoas com deficiência, em que esta simbolizava impureza, pecado ou mesmo castigo divino; b) uma fase marcada pela invisibilidade das pessoas com deficiência; c) uma terceira fase, orientada por uma ótica assistencialista, pautada na perspectiva médica e biológica de que a deficiência era uma "doença a ser curada", estando o foco no indivíduo "portador da enfermidade"; e d) finalmente uma quarta fase, orientada pelo paradigma dos direitos humanos, em que emergem os direitos à inclusão social, com ênfase na relação da pessoa com deficiência e do meio em que ela se insere, bem como na necessidade de eliminar obstáculos e barreiras superáveis, sejam elas culturais, físicas ou sociais, que impeçam o pleno exercício de direitos humanos (PIOVESAN, 2012, p. 46).

O Brasil, por sua vez, não fugiu dessa evolução que se operou no mundo todo. Com exceção do princípio formal da igualdade, que estava presente nas constituições brasileiras, “[...] alguma preocupação com esse grupo de pessoas podia ser vislumbrada nas Constituições de 1934, 1937 e 1946” (LEITE, 2016, p. 240).

Todavia, a constituição que primeiro tratou de forma expressa das pessoas com deficiência foi a de 1967. A Emenda Constitucional $n^{\circ} 12 / 78$ visava suprimir o preconceito 
e trazia comandos para a acessibilidade, ensino e trabalho, de maneira que a pessoa "deficiente" (terminologia adotada à época) pudesse se integrar à sociedade. No entanto, tal emenda nunca foi incorporada ao texto. $\mathrm{O}$ fato de estes direitos terem permanecido apartados dos demais "revela uma clara situação de falta de igualdade, pois foram deixados ao final do texto constitucional, de forma segregada" (ARAÚJO, 2014, p. 290).

De acordo com Leite (2016), somente com a Constituição Federal de 1988 que o tratamento da pessoa com deficiência se modificou, passando a ter um enfoque muito mais preocupado com a inclusão social.

\subsection{A Convenção sobre os direitos das pessoas com deficiência}

Mais recentemente, a Organização Mundial das Nações Unidas (ONU), preocupada com as sucessivas violações dos direitos humanos das pessoas com deficiência no mundo inteiro, concluiu que esse grupo demandava uma atitude institucional da comunidade internacional. Dessa forma, em 30 de março de 2007, em sua sede em Nova Iorque, assinou a Convenção sobre os Direitos das Pessoas com Deficiência e o seu Protocolo Facultativo.

A Convenção sobre os Direitos das Pessoas com Deficiência é, segundo Oliveira (2012), o documento que reconhece o valor de cada indivíduo independentemente de sua funcionalidade. A finalidade da Convenção não foi apenas a de instituir novos direitos humanos e liberdades fundamentais para as pessoas com deficiência, mas também a de "garantir que essas pessoas possam vir a desfrutá-los em igualdade de condições com todos os demais direitos, sem discriminação", conforme Leite (2016, p. 243).

Dentre os avanços instituídos, destaca-se a adoção da terminologia "pessoa com deficiência", bem mais adequada do que "pessoa portadora de deficiência", pois, de acordo com Madruga (2016) deficiência não se carrega, não se porta, não se leva consigo, como se fosse algo sobressalente ou um objeto; ela é, na verdade, inerente à pessoa que a possui. Além disso, para Araújo, (2014), a adoção de tal conceito, a partir de sua hierarquia, alterou toda a sistemática interna nacional, sendo, dessa forma, obrigatória a sua adoção.

Além do mais, a principal contribuição desta Convenção foi a positivação da mudança de paradigma da visão da deficiência no mundo, que passou do modelo médico, no qual a deficiência é tratada como uma espécie de doença, para o modelo social dos direitos humanos, no qual a deficiência engloba as limitações funcionais do corpo humano e as barreiras impostas pelo ambiente ao indivíduo. Neste ponto, Leite (2016) considera 
que o tratado reforça a ideia de que as barreiras impedem a possibilidade dessas pessoas usufruírem de seus direitos em condições de igualdade com as demais, sendo que todos os direitos ali garantidos têm o fim de emancipar as pessoas com deficiência, oportunizando a elas o pleno e o efetivo exercício e gozo de seus direitos e suas garantias fundamentais.

Por fim, importante frisar que a referida Convenção e seu Protocolo Facultativo passaram a ser o primeiro Tratado Internacional a ingressar na ordem jurídica interna brasileira com status de emenda constitucional, por ter sido aprovado seguindo a regra imposta pelo $\S 3^{\circ}$ do art. $5^{\circ}$ da Constituição Federal.

\subsection{Proteção Constitucional}

O nosso ordenamento jurídico constitucional, preocupado com o número de pessoas com deficiência, que "correspondia a $10 \%$ da população brasileira em 1988, tratou de reconhecer o processo de exclusão que vivia esse grupo, entendendo ser necessário garantir uma proteção especial" (LEITE, 2014, p. 311).

Nesse sentido, Araújo (2014) afirma que os direitos desse grupo vulnerável tiveram uma proteção que reside basicamente no direito à igualdade. Tal proteção começa no artigo $3^{\circ}$, inciso IV, da Constituição, em que é estabelecido como objetivo fundamental da república "[...] promover o bem de todos, sem preconceitos de origem, raça, sexo, cor, idade e quaisquer outras formas de discriminação".

$\mathrm{Na}$ continuidade, encontra-se também a regra geral da igualdade, presente no caput do artigo $5^{\circ}$, que afirma que todos são iguais perante a lei, sem distinção de qualquer natureza, garantindo-se aos brasileiros e aos estrangeiros residentes no País, "a inviolabilidade do direito à vida, à liberdade, à igualdade, à segurança e à propriedade" (BRASIL, 1988).

A regra matriz da igualdade constante do artigo $5^{\circ}$ já poderia ser aplicada de imediato ao grupo das pessoas com deficiência. No entanto, o legislador optou por ser específico no artigo $7^{\circ}$, inciso XXXI, que estabelece: “[...] proibição de qualquer discriminação no tocante a salário e critérios de admissão do trabalhador portador de deficiência" (ARAÚJO, 2014, p. 291).

Além disso, há outras garantias constitucionais, dentre elas a assistência social. Neste ponto, destaca-se o disposto no artigo 203:

Art. 203. A assistência social será prestada a quem dela necessitar, independentemente de contribuição à seguridade social, e tem por objetivos:

[...] IV - a habilitação e a reabilitação das pessoas portadoras de deficiência e a promoção de sua integração à vida comunitária. 
$\mathrm{V}$ - a garantia de um salário mínimo de benefício mensal à pessoa portadora de deficiência e ao idoso que comprovem não possuir meios de prover à própria manutenção ou de tê-la provida por sua família, conforme dispuser a lei. (BRASIL, 1988).

Para as pessoas com deficiência, nos dizeres de Araújo (2014), a acessibilidade funciona como um direito fundamental instrumental, ou seja, sem ela, acessibilidade, outros direitos são inviáveis de serem exercidos. Por conta disso, o constituinte no artigo $227, \S \S 1^{\circ}$ e $2^{\circ}$, estabeleceu o seguinte:

Art. 227. $\$ 1^{\circ} \mathrm{O}$ Estado promoverá programas de assistência integral à saúde da criança, do adolescente e do jovem, admitida a participação de entidades não governamentais, mediante políticas específicas e obedecendo aos seguintes preceitos:

II - criação de programas de prevenção e atendimento especializado para as pessoas portadoras de deficiência física, sensorial ou mental, bem como de integração social do adolescente e do jovem portador de deficiência, mediante o treinamento para o trabalho e a convivência, e a facilitação do acesso aos bens e serviços coletivos, com a eliminação de obstáculos arquitetônicos e de todas as formas de discriminação.

$[\ldots]$

$2^{\circ}$ A lei disporá sobre normas de construção dos logradouros e dos edifícios de uso público e de fabricação de veículos de transporte coletivo, a fim de garantir acesso adequado às pessoas portadoras de deficiência (BRASIL, 1988).

Contudo, a disciplina constitucional da acessibilidade, “embora louvável e moderna para o seu tempo, apresenta uma abordagem hoje considerada conservadora, pois restrita, basicamente, à eliminação de barreiras no acesso a estruturas físicas" (BARCELOS; CAMPANTE, 2012, p. 178).

\subsection{Legislação Infraconstitucional}

Para dar eficácia aos dispositivos constitucionais, foram editadas, dentre outras, a Lei $n^{\circ} 7.853 / 89$, o Decreto $n^{\circ} 3.298 / 99$, as Leis $n^{\circ} 10.048 / 2000$ e $n^{\circ} 10.098 / 2000$ e o Decreto ${ }^{\circ}$ 5.296/2004. De maneira geral, de acordo com Leite, (2014) toda essa legislação visa garantir à pessoa com deficiência ou mobilidade reduzida a plena integração social, com garantia de acessibilidade aos espaços da cidade.

Dentre todas, a mais específica é a Lei $\mathrm{n}^{\mathrm{o}}$ 10.098, de 19 de dezembro de 2000, que apresentou uma disciplina mais detalhada e moderna relacionada ao direito à acessibilidade. Neste contexto, “[...] a lei trouxe definições de aspectos importantes, como da acessibilidade e das barreiras" (BARCELOS; CAMPANTE, 2012, p. 179).

No entanto, somente após quatro anos foi editado o Decreto $\mathrm{n}^{\mathrm{o}} 5.296 / 04$, responsável por disciplinar a efetivação da Lei $n^{\circ}$ 10.098/02. Tal decreto regulamentador estabeleceu, segundo Leite (2014), normas gerais e critérios básicos para a promoção da 
acessibilidade das pessoas com deficiência nas edificações públicas ou privadas de uso coletivo ou multifamiliar, no espaço público, logradouros e seu mobiliário, nas comunicações e sinalizações, entre outros.

Barcelos; Campante (2012, p. 179) destacam que a Lei ${ }^{\circ} 10.098 / 02$ foi o primeiro ato normativo a tratar da acessibilidade de forma mais sintonizada com iniciativas normativas e avanços doutrinários em outros países acerca dos direitos das pessoas com deficiência.

\section{Lei brasileira de inclusão da pessoa com deficiência}

Em 2015 foi sancionada no Brasil a Lei ${ }^{\circ}$ 13.146, conhecida como Lei Brasileira de Inclusão da Pessoa com Deficiência (LBI), ou, simplesmente como Estatuto da Pessoa com Deficiência.

Depois de mais de treze anos de tramitação no Congresso Nacional, a LBI passou a ser um dos principais marcos legislativo à proteção dos direitos das pessoas com deficiência no país. "Os 127 artigos e quase trezentos novos dispositivos alteram o tratamento jurídico da questão da deficiência no país, se ancorando no arcabouço dos direitos humanos" (SANTOS, 2016, p. 3011).

De início, a LBI estabelece em seu artigo $1^{\circ}$ que a mesma é destinada a assegurar e a promover, em condições de igualdade, o exercício dos direitos e das liberdades fundamentais pelas pessoas com deficiência, visando à sua inclusão social e sua cidadania. Logo em seguida, é destacado que a lei tem como base a Convenção sobre os Direitos das Pessoas com Deficiência e seu Protocolo Facultativo, ratificados pelo Congresso Nacional por meio do Decreto Legislativo ${ }^{\circ} 186$, de 9 de julho de 2008, em conformidade com o procedimento previsto no parágrafo $3^{\circ}$ do artigo $5^{\circ}$ da nossa atual Constituição.

A LBI trouxe em seu artigo $2^{\circ}$, a definição atual de pessoa com deficiência, sendo aquela que tem impedimento de longo prazo de natureza física, mental, intelectual ou sensorial, o qual, em interação com uma ou mais barreiras, pode obstruir sua participação plena e efetiva na sociedade em igualdade de condições com as demais pessoas. Também, de forma geral, destaca-se o disposto pelo artigo $8^{\circ}$, que instituiu como dever do Estado, da sociedade e da família assegurar à pessoa com deficiência, a efetivação dos direitos referentes ao transporte, à acessibilidade, à cultura, ao desporto, ao turismo, ao lazer, à dignidade, ao respeito, à liberdade, entre outros. 
No que se refere à deficiência visual, de início a LBI traz em seu inciso V do artigo $3^{\circ}$, o conceito de comunicação, que seria a forma de interação dos cidadãos que abrange, entre outras opções, o Braille, o sistema de sinalização ou de comunicação tátil, os caracteres ampliados, além de meios e formatos aumentativos e alternativos de comunicação, incluindo as tecnologias da informação e das comunicações.

Por sua vez, o artigo 63 da referida lei garante que telecentros comunitários que receberem recursos públicos federais e lan-houses devem garantir, no mínimo, 10\% (dez por cento) de seus computadores com recursos de acessibilidade para pessoa com deficiência visual, sendo assegurado pelo menos um equipamento, quando o resultado percentual for inferior a um.

Além do mais, o art. 117 das Disposições Transitórias alterou o art. 10 da Lei $\mathrm{n}^{\circ}$ 11.126/2005, que passou a vigorar com a seguinte redação:

[...] a pessoa com deficiência visual acompanhada de cão-guia tem o direito de ingressar e de permanecer com o animal em todos os estabelecimentos abertos ao público, de uso público e privados de uso coletivo, desde que observadas as condições impostas pela Lei Brasileira de Inclusão (BRASIL, 2005).

Por conta de tantas inovações e reconhecimento de direitos, considera-se que a LBI afirmou a autonomia e a capacidade das pessoas com deficiência para exercerem atos da vida civil em condições de igualdade com as demais pessoas.

\section{Direito a acessibilidade}

A disciplina constitucional e legislativa sobre acessibilidade é bastante abrangente, tendo sido radicalmente aprofundada e modernizada pela Convenção sobre os Direitos da Pessoa com Deficiência da ONU, de acordo com Barcelos; Campante (2012). Na mesma linha, a LBI trouxe o conceito de acessibilidade em seu artigo $3^{\circ}$, inciso I:

\footnotetext{
Art. $3^{\circ}$. I - acessibilidade: possibilidade e condição de alcance para utilização, com segurança e autonomia, de espaços, mobiliários, equipamentos urbanos, edificações, transportes, informação e comunicação, inclusive seus sistemas e tecnologias, bem como de outros serviços e instalações abertos ao público, de uso público ou privados de uso coletivo, tanto na zona urbana como na rural, por pessoa com deficiência ou com mobilidade reduzida.
}

Em complementação, o artigo 53 da LBI estabelece que a acessibilidade é um direito que garante à pessoa com deficiência, ou com mobilidade reduzida, viver de forma independente e exercer seus direitos de cidadania e de participação social. De acordo com Leite (2016), a Convenção sobre Direitos das Pessoas com Deficiência consolidou a acessibilidade tanto como princípio quanto como um direito. E, segundo a mesma autora, sendo princípio-direito, obriga os Estados à sua implementação como garantia 
fundamental, extremamente relevante para a concretização dos direitos humanos das pessoas com deficiência.

Nesta direção, Barcelos; Campante (2012) afirmam que não é possível falar em direito das pessoas com deficiência à educação, à saúde, à inserção no mercado de trabalho, dentre outros, sem o acesso a tais direitos. A acessibilidade é reconhecida, portanto, como uma precondição ao exercício dos demais direitos, sendo tanto um direito em si quanto um direito instrumental. Além do mais, Leite (2016) considera a acessibilidade um direito fundamental, pois a sua presença no meio urbano, bem como nas edificações, nos transportes e nas suas mútuas interações é uma exigência constitucional.

É importante destacar que a acessibilidade abrange não apenas as estruturas físicas, mas também todas as demais esferas de interação social, pois em seu significado moderno, a acessibilidade é reconhecida como a adoção de um conjunto de medidas capazes de eliminar todas as barreiras sociais. Neste ponto, Sassaki (2009) afirma que a acessibilidade é uma qualidade que envolve todos os contextos e aspectos da atividade humana, e, por isso, estabeleceu as seis dimensões da acessibilidade, que são as seguintes:

[...] arquitetônica (sem barreiras físicas), comunicacional (sem barreiras na comunicação entre pessoas), metodológica (sem barreiras nos métodos e técnicas de lazer, trabalho, educação etc.), instrumental (sem barreiras instrumentos, ferramentas, utensílios etc.), programática (sem barreiras embutidas em políticas públicas, legislações, normas etc.) e atitudinal (sem preconceitos, estereótipos, estigmas e discriminações nos comportamentos da sociedade para pessoas que têm deficiência) (SASSAKI, 2009, p. 1).

Ademais, Leite (2014) pondera que a pessoa com deficiência somente usufruirá de seus direitos se tiver uma cidade que seja acessível, isto é, uma cidade em que a pessoa com deficiência consiga se locomover, se deslocar livremente pelos seus espaços. Apesar de toda legislação existente, Barbosa (2016) identificou em pesquisa diversas dificuldades enfrentadas pelos deficientes visuais no que se refere à acessibilidade, dentre elas a ausência de sinal sonoro e calçadas cheias de obstáculos, mal conservadas ou inacabadas.

O desenho universal é uma estratégia de enfrentamento desse tipo de dificuldades e obstáculos à acessibilidade. Assim, o artigo $3^{\circ}$ da LBI, em seu inciso II, define desenho universal como a concepção de produtos, ambientes, programas e serviços a serem usados por todas as pessoas, sem necessidade de adaptação ou de projeto específico, incluindo os recursos de tecnologia assistiva.

Segundo Sassaki (2009), se a acessibilidade for, ou tiver sido, projetada sob os princípios do desenho universal, ela beneficia todas as pessoas, tenham ou não qualquer tipo de deficiência. Todavia, Barbosa (2016) destaca que muitas pessoas com deficiência, 
em várias partes do Brasil, encontram obstáculos que dificultam ou impossibilitam sua mobilidade, restringindo-as ao seu ambiente doméstico e cerceando sua independência, sua capacidade de ter uma vida produtiva e seu direito de ir e vir.

Importante salientar que é o Município o principal responsável pela tomada de decisões e das ações executivas das políticas de acessibilidade, afinal cabe a ele a promoção do adequado ordenamento territorial, nos ensinamentos de Leite (2016).

Conforme Barcelos; Campante (2012), as possíveis dificuldades de operacionalização da acessibilidade não podem ser pretexto para a manutenção da realidade de discriminação no acesso à convivência social, pois, sendo a acessibilidade um direito fundamental, a sua concretização não pode estar sujeita a um juízo de conveniência.

\section{Dificuldades e perspectivas da acessibilidade do deficiente visual}

Apesar de toda legislação existente, Barcelos; Campante (2012) ressaltam que um dos principais desafios enfrentados pelas iniciativas de implementação da acessibilidade é o de produzir espaços, tecnologias e serviços que sejam realmente capazes de permitir a sua fruição por todas as pessoas.

Dentre os diferentes grupos sociais cujas necessidades devem ser supridas pelo Estado, encontram-se os deficientes visuais. Com efeito, a falta de acessibilidade nos espaços e vias públicas, no mobiliário urbano, nos transportes, nos meios de comunicação, nas tecnologias e nas sinalizações, faz com que essas pessoas fiquem confinadas em suas casas. "Sem os espaços adaptados, não se tem acessibilidade, e, sem esta, não há direitos iguais, não há inclusão social" (LEITE, 2016, p. 245).

Assim, será que podemos falar em liberdade e principalmente, em igualdade, se uma pessoa com deficiência visual necessita ser conduzida pelo braço de estranhos para caminhar pelas vias públicas, ou outros espaços públicos que se encontram em situações que impedem a livre e segura circulação?

As pessoas que necessitam do auxílio de outras para alcançar seus objetivos, não vivenciam a essência do conceito da acessibilidade universal em nenhum momento. "Somente há que se falar em inclusão das pessoas com deficiência ou mobilidade reduzida se houver acessibilidade com autonomia e independência" (LEITE, 2016, p. 248).

Exemplificando, conforme Affonso (2016), apesar do direito de acesso à cultura e lazer, obras culturais muitas vezes não são acessíveis às pessoas com deficiência visual, porque não são disponibilizadas em um formato de áudio, braile ou corpo aumentado, no 
caso de livros e revistas, ou não é feita a audiodescrição de obras em museus, de filmes em cinemas e de imagens em exposições fotográficas.

Em que pese o direito do portador de deficiência visual de ingressar e permanecer em ambientes de uso coletivo acompanhado de cão-guia, atualmente, existem apenas 160 cães-guia treinados e prontos para auxiliar seus donos no Brasil. O motivo, de acordo com a autora, "[...] é que existem poucos centros de treinamento, o que torna conseguir um cãoguia algo raro e caro" (FREITAS, 2016).

Assim, como destaca Oliveira Júnior (2016), muitas vezes o portador de deficiência visual opta pelo uso da bengala, mas as calçadas irregulares, os degraus imprevisíveis e até mesmo os obstáculos de maior porte, como um orelhão, não são alcançados pelo seu tatear.

Em consequência, a cidade e seus espaços, quando não são acessíveis para as pessoas com deficiência, deixam de ser o local de convívio, de encontro, da troca, do compartilhamento (espaços de inclusão social), para tornarem-se locais de exclusão espacial. No entanto, as pessoas com deficiência são pessoas como todas as outras e merecem respeito e consideração por parte do Estado e da comunidade.

\section{Considerações Finais}

Apesar de todo o avanço legal em matéria de acessibilidade das pessoas com deficiência, não é suficiente apenas a mudança na legislação para solucionar os problemas sociais decorrentes da exclusão dessa parcela da sociedade. Assim, a modificação deve ocorrer, também, na consciência de todos os membros da sociedade.

Conforme o exposto neste estudo, os deficientes sofreram durante longos períodos da história, tendo sido negligenciados e excluídos. Apenas recentemente os Estados e a sociedade se atentaram para a necessidade de inclusão e emancipação social dessas pessoas.

A Convenção sobre os Direitos das Pessoas com Deficiência da ONU se revela como um divisor de águas na luta pela acessibilidade. No Brasil, tal convenção foi acolhida com força de emenda constitucional, além de ter sido base e inspiração para a criação da LBI. Apesar de tantos direitos garantidos em lei, o deficiente visual, como vimos, enfrenta a dura realidade da exclusão. É possível observar que diversas cidades brasileiras não possuem o mínimo de acessibilidade.

Historicamente, escolas, hospitais, calçadas, parques, museus, estádios, dentre outros espaços urbanos, não foram planejados de forma acessível aos deficientes visuais. 
Ademais, os novos espaços que vem sendo criados nem sempre atendem as necessidades deste público.

Infelizmente, no Brasil algumas leis são ignoradas pela sociedade e pelo poder público. Assim, surge a necessidade de se lutar para que a LBI seja observada no país em todas as esferas, mas principalmente pelos gestores municipais, que, podem gerar as mudanças mais palpáveis, como a implantação de sinalização tátil e semáforos sonoros.

Neste contexto, a LBI não consegue reparar sozinha a falta de inclusão das pessoas com deficiência visual na sociedade, principalmente no que se refere ao direito à acessibilidade que, conforme exposto, é um direito fundamental e instrumental de outros direitos.

Conclui-se que, apesar das garantias constitucionais e dos avanços tragos pela LBI, os deficientes visuais ainda vivem uma realidade de exclusão e desigualdade, pois, sem acessibilidade essas pessoas não conseguem usufruir de seus direitos.

Dessa forma, surge a necessidade de planejamento e implantação de medidas efetivas que assegurem o direito fundamental à igualdade e à acessibilidade, e em consequência, o acesso ao esporte, a cultura, ao lazer e ao transporte público com as mesmas oportunidades do restante da população. 


\section{REFERÊNCIAS}

AFFONSO, Debora Kelly. Do direito à cultura, ao esporte, ao turismo e ao lazer. In: LEITE, Flávia Almeida (Org.). Comentários ao Estatuto da Pessoa com Deficiência. São Paulo: Saraiva, 2016. Cap. 9, p. 199-219.

ALMEIDA, Luiz Cláudio Carvalho de. Do direito ao transporte e à mobilidade urbana. In: LEITE, Flávia Almeida (Org.). Comentários ao Estatuto da Pessoa com Deficiência. São Paulo: Saraiva, 2016. Cap. 10, p. 220-235.

ARAUJO, Luiz Alberto David. Painel sobre os direitos das pessoas com deficiência no sistema constitucional brasileiro. In: CAVALCANTI, Ana Elizabeth Wanderley; LEITE, Flávia Almeida; LISBOA, Roberto (Org.). Direitos da infância, juventude, idoso e pessoas com deficiência. São Paulo: Editora Atlas, 2014. Cap. 17, p. 289-296.

BARBOSA, Adriana Silva. Mobilidade urbana para pessoas com deficiência no Brasil: um estudo em blogs. urbe, Rev. Bras. Gest. Urbana, Curitiba, v. 8, n. 1, p. 142-154, apr. 2016. Disponível em: http://www.scielo.br/scielo.php?script=sci_arttext\&pid=S2175$33692016000100142 \& \operatorname{lng}=e n \& n r m=$ iso. Acesso em: 25 de ago. 2017

BARCELlOS, Ana Paula de; CAMPANTE, Renata Ramos. A acessibilidade como instrumento de promoção de direitos fundamentais. In: FERRAZ, Carolina Valença (Org.). Manual dos direitos da pessoa com deficiência. São Paulo: Saraiva, 2012. Cap. 2, p. 175-191.

BARRETO JÚNIOR, Irineu Francisco. Inclusão da pessoa com deficiência e a realidade brasileira. In: CAVALCANTI, Ana Elizabeth Wanderley; LEITE, Flávia Almeida; LISBOA, Roberto (Org.). Direitos da infância, juventude, idoso e pessoas com deficiência. São Paulo: Atlas, 2014. Cap. 18, p. 297-307.

BRASIL. Constituição da República Federativa Brasileira. Promulgada em 05 de outubro de 1988. Diário Oficial da União, Brasília, 05 de outubro de 1988. Disponível em: http://www.planalto.gov.br/ccivil_03/constituicao/constituicao.htm. Acesso em: 25 de ago. 2017.

BRASIL. Constituição da República Federativa Brasileira. Decreto 3.298 de 1999. Regulamenta a Lei 7.853 de 1989, dispõe sobre a Política Nacional para a Integração da Pessoa Portadora de Deficiência, consolida as normas de proteção, e dá outras providências. Diário Oficial da União, Brasília, 20 de dezembro de 1999. Disponível em: http://www.planalto.gov.br/ccivil_03/decreto/d3298.htm. Acesso em: 25 de ago. 2017.

BRASIL. Constituição da República Federativa Brasileira. Lei 11.126 de 2005. Dispõe sobre o direito do portador de deficiência visual de ingressar e permanecer em ambientes de uso coletivo acompanhado de cão-guia. Diário Oficial da União, Brasília, 06 de Julho de 2015. Disponível em: http://www.planalto.gov.br/ccivil_03/_ato20042006/2005/lei/l11126.htm. Acesso em: 25 de ago. 2017.

BRASIL. Constituição da República Federativa Brasileira. Lei 13.146 de 2015. Institui a Lei Brasileira de Inclusão da Pessoa com Deficiência (Estatuto da Pessoa com 
Deficiência). Diário Oficial da União, Brasília, 06 de julho de 2015. Disponível em: http://www.planalto.gov.br/ccivil_03/_ato2015-2018/2015/lei/113146.htm. Acesso em: 25 de ago. 2017.

CAVALCANTI, Ana Elizabeth Wanderley; LEITE, Flávia Almeida; LISBOA, Roberto. Direitos da infância, juventude, idoso e pessoas com deficiência. São Paulo: Atlas, 2014.

FONSECA, Ricardo Tadeu Marques da. O novo conceito constitucional de pessoa com deficiência: um ato de coragem. In: FERRAZ, Carolina Valença (Org.). Manual dos direitos da pessoa com deficiência. São Paulo: Atlas, 2014. Cap. 1, p. 19-32.

FRANCO, Simone. Lei Brasileira de Inclusão entra em vigor e beneficia 45 milhões de pessoas. Senado Federal. Disponível em:

http://www12.senado.leg.br/noticias/materias/2016/01/21/lei-brasileira-de-inclusao-entraem-vigor-e-beneficia-45-milhoes-de-brasileiros Acesso em 08 de set. 2017.

FREITAS, Hyndara. Brasil tem 6 milhões de pessoas com deficiência visual, mas apenas 160 cães-guia. Disponível em:

http://emais.estadao.com.br/noticias/comportamento,brasil-tem-6-milhoes-de-pessoascom-deficiencia-visual-mas-apenas-160-caes-guia,10000094416. Acesso em: 10 de set. 2017.

LEITE, Flávia Almeida. Comentários ao Estatuto da Pessoa com Deficiência. São Paulo, SP. Saraiva, 2016.

LISBOA, Roberto Senise. Acesso à informação digital para deficientes visuais. In: CAVALCANTI, Ana Elizabeth Wanderley; LEITE, Flávia Almeida; LISBOA, Roberto (org.). Direitos da infância, juventude, idoso e pessoas com deficiência. São Paulo: Atlas, 2014. Cap. 21, p. 342-361.

MADRUGA, Sidney. Pessoas com deficiência e direitos humanos: ótica da diferença e ações afirmativas. 2. ed. São Paulo: Saraiva, 2016.

MATOS, Fernando. Tipos de Deficiência Visual. 2012. Disponível em: https://www.news-medical.net/health/Types-of-visual-impairment-

\%28Portuguese\%29.aspx. Acesso em: 04 de set. 2017.

OLIVEIRA JÚNIOR, Eudes Quintino de; OLIVEIRA, Pedro Bellentani Quintino de. O portador de deficiência visual e o cão-guia. Disponível em:

http://www.migalhas.com.br/dePeso/16,MI238421,81042O+portador+de+deficiencia+visu al+e+o+caoguia. Acesso em: 10 de set. 2017.

OLIVEIRA, Luiza Maria Borges. Cartilha do Censo 2010 - Pessoas com Deficiência. Brasília, 2012. Disponível em:

http://www.pessoacomdeficiencia.gov.br/app/sites/default/files/publicacoes/cartilha-censo2010-pessoas-com-deficienciareduzido.pdf. Acesso em: 04 de set. 2017. 
PIOVESAN, Flávia. Convenção da ONU sobre os direitos das pessoas com deficiência: inovações, alcance e impacto. In: FERRAZ, Carolina Valença (Org.). Manual dos direitos da pessoa com deficiência. São Paulo: Saraiva, 2012. Cap. 2, p. 33-51.

SANTOS, Wederson. Disability as a restriction on social participation: challenges in evaluation since the Brazilian Inclusion of People with Disabilities Act. Ciênc. saúde coletiva, Rio de Janeiro, v. 21, n. 10, p. 3007-3015, oct. 2016. Disponível em: http://www.scielo.br/scielo.php?script=sci_arttext\&pid=S141381232016001003007\&lng= en\&nrm=iso. Acesso em: 25 de ago. 2017.

SASSAKI, Romeu Kazumi. Inclusão: acessibilidade no lazer, trabalho e educação. Revista Nacional de Reabilitação (Reação), São Paulo, Ano XII, p. 10-16, mar./abr. 2009. 